\title{
SOLAR CHARGING EV SYSTEM
}

\author{
Ranveer Singh Chouhan \\ E-Mail Id: rs.chouhan.3105@gmail.com \\ Department of Electrical Engineering, Aravali Institute of Technical Studies, Udaipur, India
}

\begin{abstract}
As worlds resources are diminishing, govt. agencies and nongovernment organization are pushing greener solution through the use of renewable energy's sources, as electric power must become less dependent on fossils fuel and transportation must become more electric to decrease carbon emission and mitigate climate change. Hence in order to reduce the pollution through the motor vehicles, electric vehicles are being invented and in order to run the electric vehicle the fuel required is the electricity which can be storable through the use of solar energy and run these electric vehicles through the Electric vehicle smart charging station which is the promising alternative and environmentally sustainable solution to meet up the energy crisis. As worlds resources are diminishing, govt. agencies and nongovernment organization are pushing greener solution through the use of renewable energy sources, as electric power must become less dependent on fossils fuel and transportation must become more electric to decrease carbon emission and mitigate climate change. Hence in order to reduce the pollution through the motor vehicles, electric vehicles are being invented and in order to run the electric vehicle the fuel required is the electricity which can be storable through the use of solar energy and run these electric vehicles through the electric vehicle smart charging station which is the promising alternative and environmentally sustainable solution to meet up to the energy crisis.
\end{abstract}

Keywords: sunlight-solar panel-charge controller-battery-charging point.

\section{INTRODUCTION}

Few years ago electric vehicles were invented in India to reduce the excess use of fossil fuel and to reduce the harmful emissions emitted from the electric vehicles. But in order to run this electric vehicles the fuel required for running vehicle was electric energy which is obtain from grid but the grid energy is also limited and it is not easily available hence it was the main disadvantage but due to the development of the charging stations this effect was also neglected hence the charging station is very efficient. Fast charging stations will be needed to facilitate longer EV travel distances, including inter-regional trips. They should be placed in larger cities where there is a concentrated population of EV drivers so stations can also be used by local residents. The planning for fast charging stations should be coordinated at the State level and attempt to align with regular routes for government or private fleets of EVs.

Electric vehicle smart charging station which is the promising alternative and environmentally sustainable solution to meet up the energy crisis. As worlds resources are diminishing, govt. agencies and nongovernment organization are pushing greener solution through the use of renewable energy sources, as electric power must become less dependent on fossils fuel and transportation must become more electric to decrease carbon emission and mitigate climate change. Hence in order to reduce the pollution through the motor vehicles, electric vehicles are being invented and in order to run the electric vehicle the fuel required is the electricity which can be storable through the use of solar energy and run these electric vehicles through the electric vehicle smart charging station which is the promising alternative and environmentally sustainable solution to meet up to the energy crisis.

\section{LITERATURE SURVEY}

With the development of the global economy, the demand and consumption of energy in various countries have been growing steadily. Environmental pollution and the energy crisis have also attracted attention. According to a survey from the World Bank, CO2 emissions in 2013 and 2014 were 4.988 and 4.97 metric tons per capita, respectively. The high $\mathrm{CO} 2$ emissions are mainly a result of the coal-based energy structure.

More than half of petroleum is used in transportation. Fuel vehicles account for the largest proportion of the transportation sector. At the same time, the automobile exhaust is one of the main sources of environmental pollution.

The development of the electric vehicle (EV) industry is an important measure to reduce greenhouse gas emissions and reduce dependence on fossil fuels. With the advance of EV technology, especially the development of battery technology, and the strong policy support in some countries, EVs have developed rapidly over the past decade.

Many EVs increase the load in power grids, which will have a negative impact on the safe and reliable operation of power systems. However, except for these negative effects, EVs can bring considerable economic benefits to the distribution system through optimal planning, such as vehicle-to-grid (V2G) technology. According to statistics, the driving time of $80 \%$ of vehicles is about $1 \mathrm{~h}$ per day, and they are idle for $95 \%$ of the day. The energy stored in EVs is considerable.

\section{CONNECTION DIAGRAM OF CHARGING STATION}

Recharging EVs is accomplished through connections to electric vehicle charging equipment, also referred to as Electric Vehicle Supply Equipment (EVSE). This is a protective system which communicates with the vehicle and monitors electrical activity to ensure safe charging. While the actual "charger" is contained in the vehicle, the appliance commonly referred to as a charging station or EVSE is the conduit, control, and monitoring device which connect the vehicle to the electric grid.

1.2 is a diagram of the overall charging energy flow from the power grid, through the EVSE (shaded in orange) and into the vehicle through the industry standard J1772 port connector. With alternating current (AC) EVSE, charger electronics within the vehicle invert the AC power supplied by the EVSE into direct current (DC) for storage in the 
battery. Fast charging DC delivers high voltage (typically over $400 \mathrm{~V}$ ) direct current straight to an electric vehicle's battery system.

\section{CIRCUITS ANALYSIS}

\subsection{Solar Panel}

Solar panels and electric cars are a match made in heaven - when you install a solar energy system on your home, you can use it to both power your home and charge your electric car for emissions-free transportation. The cost of solar is falling rapidly, and companies from Tesla to Nissan are manufacturing electric cars for your daily use. Now, the ability to install a solar PV system large enough to power both your home and your car is an option within reach. But even with incentives and rebates available for both technologies, most homeowners still can't afford to install solar and buy an electric car at the same time. Luckily, it's easy to install a solar energy system today that takes your future electricity consumption into account, if you take a few additional factors into consideration.

\subsection{Charge Controller}

The Charge Controller is a switching device that can connect and disconnect the charger to the battery and it will take control over charging and to stop charging at the correct voltage. This will protect the batteries from damage from overcharging and regulate the power going from the solar panels to the batteries. A microcontroller in the circuit will read the level of the batteries and then cut off the source of the solar panels to the batteries, once it sees the battery is at the fully charged state. If this was not in place, the solar panels would keep feeding the batteries energy and the batteries would become overheated and damage the internal components.

The advantage to have a microcontroller in the system is that it will open a variety of features to add to the system. For example the microcontroller will be programmed to control and display the battery level of the system. It will ensure that there is enough power to charge devices by displaying the gauge on a 7 segment LCD. If there is insufficient power, it will prevent the system from being used until sufficient power has been reached. The microcontroller will also be used in aiding solar efficiency by controlling the solar tracker, as mentioned previously.

\subsection{Battery}

The team has selected two deep cycle batteries to power the system. Each battery is a $12 \mathrm{~V}$ and has a 35 Amp-hour capacity. Batteries for PV system batteries generally have to discharge a smaller current for a longer period of time, such as at night or during a power outage, while being charged during the day. Deep cycle batteries are designed for the purpose of discharging to a lower capacity, between $50 \%$ and $80 \%$, than a conventional battery. The most commonly used deep-cycle batteries are lead-acid batteries and nickel-cadmium batteries, both of which have pros and cons. The deep cycle batteries are able to be easily charged and discharged many times and can last for several years due to the thicker plate materials utilized. Batteries in PV systems can also be very dangerous because of the energy they store and the acidic electrolytes they contain, so you'll need a well-ventilated, nonmetallic enclosure for them.

\subsection{Charging Socket}

Europeans operate at $220 \mathrm{~V} 50 \mathrm{~Hz}$ and the Americans operate at $110 \mathrm{~V} 60 \mathrm{~Hz}$ the EVs also have different types of charging connectors based on the country it is manufactured form. This has lead to confusion among ESVE manufacturers as they cannot be made universal easily for all EVs. The main classifications of Connectors for AC chargers and DC chargers.

\subsection{Inverter Circuit}

An inverter is an integral component in the solar station' design. It will convert the DC voltage generated from the solar panels to an AC voltage. The team will be testing two designs by using special ICs or several pairs of transistors and diodes. An inverter can produce square wave, modified sine wave, pulsed sine wave, or sine wave depending on circuit design, demonstrated in Figure 2. The two dominant commercialized waveform types of inverters as of 2007 are modified sine wave and sine wave. There are two basic designs for producing household plug-in voltage from a lower voltage DC source, the first of which uses a switching boost converter to produce a higher-voltage DC and then converts to AC. The second method converts DC to AC at battery level and uses a line-frequency transformer to create the output voltage.

Inverter circuits can have a power loss of $10 \%$ or even up to $20 \%$. The team anticipates for a larger power inverted based on our maximum expected output and that the largest output will be required when two laptops are plugged into the system. Generally, laptops can draw anywhere between 65-90 Watts. For two laptops rated at 90 Watts, the inverter will be required to generate 180 Watts. From our calculation, we determined a 200 Watt inverter will suffice. At a $90 \%$ efficiency (10\% power loss), the inverter will generate the 180 Watts we need.

\section{CONCLUSION}

This project has budgetary restrictions as an initially presented. Most Senior Design projects use industry sponsored projects as a way to introduce the student to working under real industry guidelines and also for companies to be introduced to the next generation of potential employees. This solar station concept came from students; no industry sponsor was involved in the thought process of the design. Our team has contacted several industry sponsors and is in the works of negotiating a sponsor. Having an industry sponsor gives the students a technical supervisor and collaborator to assist with any research and design issues that may arise in addition to financial support. Eliminating dependence on fossil fuels and limited resources while designing an environmentally friendly, self-sustainable, outdoor energy source is the goal for the solar powered charging station.. The team's research indicated a benefit to the campus 
for such a structure and also room for improvement on other existing charging stations. The other stations the team found to exist were quite costly to build. As well, rapidly advancing solar innovations and designs could lend themselves to creating a more efficient charging station.

\section{REFERENCES}

[1] Canadian Standards Association, 2010. Québec Construction Code, Chapter V - Electricity.Canadian Electrical Code, Part One with Québec Amendments (C 22.10-10), 21st edition, Section 86.

[2] Kissel, Gery. August 2011. Presentation of Standard J 1772 at the Infrastructure Working Council Conference.

[3] CHAdeMO, Technical Specifications of Quick Charger for the Electric Vehicle. Rev. 0.9, p. 76.

[4] S A E International, January 2010 SAE Electric Vehicle and Plug In Hybrid Vehicle Conductive Charge Coupler. S A E Standard J 1772-2010.

[5] CHAdeMO, Technical Specifications of Quick Charger for the Electric Vehicle. Rev. 0.9. 6.Online: [http://chademo.com/ 01_CHAdeMO_Chargers.html] (Accessed on August 18, 2011).

[6] Online: AddÉnergie Technologies, Technical data sheet for the SmarTwo ${ }^{\text {TM }}$ charging station. [http://addenergietechnologies. com/_en/Documents/smarttwo-addenergie-spec-smartwo-v1-1-2012-01-01.pdf]

[7] Canadian Standards Association, 2010. Québec Construction Code - Chapter V, Electricity. Canadian Electrical Code, Part One with Québec Amendme nts (C 22.10-10), 21 st edition, Rule 86-304.

[8] Corporation des maîtres électriciens du Québec (C M E Q), 2010. "Chutes de tension" [voltage drop] calculation tool, C M E Q Web site (in French only), Montréal, C M E Q. [https://www.cmeq.org/calculateurs/ch utes.htm] (Accessed on November 21, 2011). 